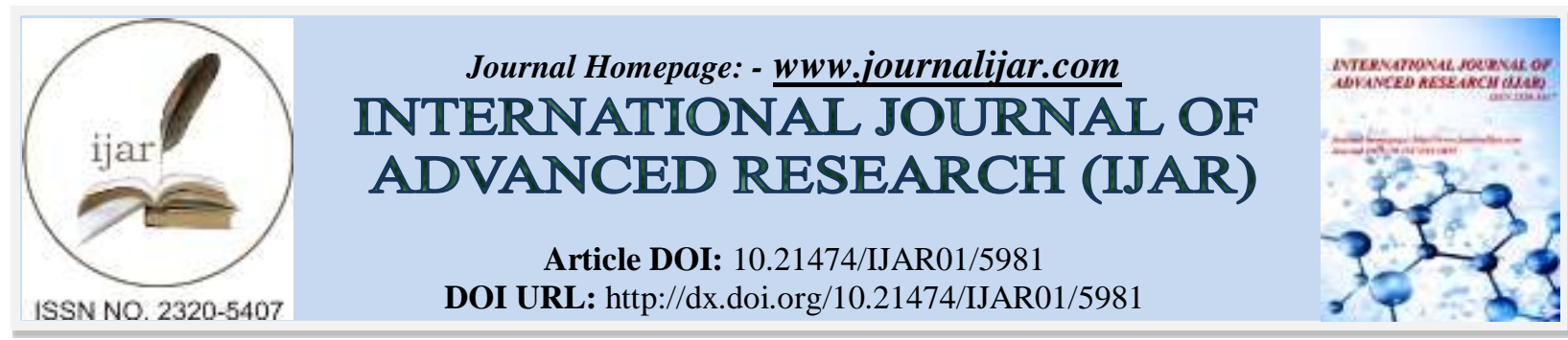

RESEARCH ARTICLE

\title{
EARLY NEUROLOGICAL COMPLICATIONS AFTER CORONARY BYPASS SURGERY.
}

\author{
Hashem H. A., MD ${ }^{1}$, Yasser Hamed Mostafa, $\mathrm{MD}^{2}$ and Peter Bodlak, MD ${ }^{3}$. \\ 1. Hassan Ahmed Hashem, Lecturer of neurology, Al- Azhar faculty of medicine, Assiut branch. \\ 2. Yasser Hamed Mostafa: Lecturer of neurology, Al- Azhar faculty of medicine, Assiut branch. \\ 3. Peter Bodlak, MD, cardiac surgery, Bugshan hospital, Jeddah, KSA.
}

\section{Manuscript Info}

Manuscript History

Received: 06 October 2017

Final Accepted: 08 November 2017

Published: December 2017

Key words:-

CABG, Dyslipidemia, Stroke,

complications, BMI

\begin{abstract}
Background: Coronary Artery Bypass Graft surgery (CABG) is one of the most common surgery procedures performed annually in worldwide. The objective of this study is to determine the prevalence and risk factors of the early neurologic complications emerged after CABG surgery. Materials and Methods: In a prospective study we have investigated 134 patients undergoing CABG between July 2016 and June 2017 in cardiac surgery ward, Bugshan hospital, Jeddah, KSA. Risk factors that evaluated in our analysis consist of hypertension (HTN), diabetes, body mass index (BMI), dyslipidemia and severity of carotid artery stenosis. Our dependent variables were change in conscious level, CVA and seizure. Results: In our analysis, of total 134 patients, $14(10.4 \%)$ were female. Mean age of patients was $57 \pm 20$ years. Of total patients, $72(53.7 \%)$ were found to have HTN, 82 (61.2\%) had diabetes, $110(82.1 \%)$ had dyslipidemia, $6(4.5 \%)$ significant $(\geq 50 \%)$ carotid stenosis and $112(83.6 \%)$ had abnormal [ $\left(\geq 25 \mathrm{~kg} / \mathrm{m}^{2}\right)$ BMI, $\left(40.3 \%\right.$ were overweight (BMI $\geq 25$ and $\left.<30 \mathrm{~kg} / \mathrm{m}^{2}\right)$, $35.8 \%$ obese (BMI $\geq 30$ and $<35 \mathrm{~kg} / \mathrm{m}^{2}$ ) and $7.5 \%$ severely obese (BMI $\left.\left.\geq 35 \mathrm{~kg} / \mathrm{m}^{2}\right)\right]$. The incidence rate of change in sensorium after CABG was 6 (4 was diagnosed as HIE and 2 with NCSE) and for CVA were 6 (4.5\%). Dyslipidemia. BMI and HTN were the important risk factors. Conclusion: According to this analysis, Dyslipidemia, BMI and HTN were the most important risk factors of neurological complications after CABG.
\end{abstract}

Copy Right, IJAR, 2017,. All rights reserved.

\section{Introduction:-}

Coronary Artery Bypass Graft (CABG) surgery is one of the most prevalent surgeries performed annually throughout the world. More than 500000 CABG surgeries are performed in the U.S. annually ${ }^{1}$. Neurological complications are a major cause of morbidity and mortality during the immediate postoperative period following cardiac surgery ${ }^{2}$. Those individuals undergoing these surgeries are mostly of the elderly people suffering from coronary artery disease and are undergone the surgery either as an emergency surgery or an elective surgery. This surgery comes with some complications as is the case for other surgeries which the neurologic and cognitive complications constitute an important portion of these complications. The neurologic complications like the stroke and impaired sensorium are regarded as the most prevalent and important complications occurred after CABG which can also affect the patient's quality of life at next years and increase the patient's hospital stay ${ }^{3,4}$. Based on the 
performed studies, the incidence rate of stroke after CABG surgery is in the range $0.8-5.2 \%{ }^{5}$. Moreover, the incidence time of stroke after CABG surgery varies considerably. Those patients who are affected with stroke after surgery have poor prognoses compared to those without this complication. However, etiology of stroke after CABG varies and some factors such as hypertension, diabetes, old age, dyslipidemia and stroke background are regarded as the stroke's risk factors after $\mathrm{CABG}^{6}$. In a previously performed study, the death risk of patients affected with stroke was three times higher than those without stroke ${ }^{7}$. Aside from stroke, differing degrees of decrease in the level of consciousness (which we will refer to as encephalopathy), a more or less evident deterioration in neuropsychological function and convulsive seizures may be observed during the immediate postoperative period following cardiac surgery ${ }^{8}$. The cause of many of the neurological complications of open heart surgery has not been determined, but mounting evidence has pointed to ischemic events secondary to micro-emboli. A trans-cranial Doppler ultrasound investigation provided evidence for micro-emboli in the middle cerebral artery during cardiopulmonary bypass ${ }^{9}$.

\section{Methods:-}

The study cohort comprised 134 patients who underwent elective CABG surgery during the 12-month period from July 2016 to June 2017 in cardiac surgery ward, Bugshan hospital, Jeddah, KSA. There were 14 women (10.4\%) and 120 men (89.6\%). Aged 37-77 (mean 57 \pm 20 ) years. Detailed history and clinical neurologic assessment of all patients was undertaken in the 2 days prior to surgery to identify preoperative neurologic abnormalities and to define previous episodes of neurologic illness and possible risk factors for neurologic complications of surgery (Age, DM, HTN, weight and height), BMI was calculated, lipid profile and color Doppler-ultrasound for carotid arteries (existence of atherosclerosis disease in carotid arteries, artery stenosis reported as percent diameter stenosis of the carotid artery) were done for all patients ( $\geq 50 \%$ stenosis considered significant). Postoperatively the patients were seen and neurologically assessed on a daily basis until discharge from the hospital. Our dependent variables were change in conscious level, Cerebro-vascular accident (CVA) and seizure. Patients with prior CVA and those died during or shortly after procedure were excluded from this study. The postoperative CVA and seizure were evaluated by using the examination of patients and evaluation of brain CT scan and EEG tests results. Brain CT and EEG were done for patients they developed neurological abnormalities. The data recording was in an anonymous manner and the participation in the study was voluntary and optional. Moreover, the above-mentioned plan was matched with the format approved by the Ethics Committee of Bugshan hospital. The statistical analysis was done using the Chisquared test with the p-Value less than 0.05 considered significant. This analysis was performed using the SPSS-16 software.

\section{Results:-}

In this study, 134 patients undergoing CABG between July 2016 and June 2017 in Bugshan hospital, Jeddah, KS A were investigated. Of total 134 patients, $14(10.4 \%)$ and $120(89.6 \%)$ were female and male respectively. Mean age of the patients was $57 \pm 20$ years. Of total 134 studied patients, $6(4.5 \%)$ and $6(4.5 \%)$ people were affected with change in conscious level (4 patient was diagnosed as hypoxic ischemic encephalopathy and 2 patient were diagnosed as non-convulsive status epilepticus) and CVA respectively. In the performed examination, of total 134 patients, $72(53.7 .4 \%)$ were found to have HTN, $82(61.2 \%)$ had diabetes, $110(82.1 \%)$ had dyslipidemia, $6(4.5 \%)$ significant $(\geq 50 \%)$ carotid stenosis and $112(83.6 \%)$ had abnormal $\left(\left(\geq 25 \mathrm{~kg} / \mathrm{m}^{2}\right)\right.$ BMI, $(40.3 \%$ were overweight $\left(\mathrm{BMI} \geq 25\right.$ and $<30 \mathrm{~kg} / \mathrm{m}^{2}$ ), $35.8 \%$ obese (BMI $\geq 30$ and $<35 \mathrm{~kg} / \mathrm{m}^{2}$ ) and $7.5 \%$ severely obese (BMI $\geq 35 \mathrm{~kg} / \mathrm{m}^{2}$ ). Regarding the six patients with depressed consciousness (4 patients with HIE and 2 patients with NCSE) 4 patients was with DM, 2 patients were with HTN, all patients were dyslipidemic, 4 patients were obese and 2 were overweight, 2 patients were with significant carotid stenosis $(\geq 50 \%)$ and were aged 57,58 and 72 year old, of total population of women and men, 4 woman ( $28.6 \%$ of women) and 2 men (1.7\% of men) had been affected after the CABG surgery (table 1). Regarding CVA (all were ischemic) 4 patients were with DM, 2 patients were with HTN, 4 patients were dyslipidemic, 2 patients were obese and 4 were overweight, 2 patients were with significant carotid stenosis $(56 \%)$ and were aged 55, 74 and 76 year old, of total population of women and men, 6 men (5\% of men) had been affected with CVA after the CABG surgery, no woman was affected with CVA (table 2). Regarding investigation results were done for affected 12 patients (6 with change in conscious level and 6 with CVA), CT brain showed ischemic cerebrovascular strokes, in different vascular territories, no hemorrhagic strokes were seen, (figures 1-6). Regarding the 6 patients with depressed consciousness, CT brain was unremarkable in all patients and EEG was showed picture of non-convulsive status epilepticus in 2 patients and diffuse encephalopathy in the other four. 
Table (1):- Correlation between risk factors and change in consciousness

\begin{tabular}{|l|l|c|l|}
\hline Risk factor & No. of patients & Complications (no) & P. value \\
\hline HTN & $72(53.7 \%)$ & $2(2.7 \%)$ & $0.0177^{*}$ \\
\hline DM & $82(61.2 \%)$ & $4(4.9 \%)$ & $0.0006^{*}$ \\
\hline dyslipidemia & $110(82.1 \%)$ & $6(5.5 \%)$ & $0.0001^{*}$ \\
\hline Abnormal BMI & $112(83.6 \%)$ & $6(5.4 \%)$ & $0.0001^{*}$ \\
\hline Signif. carotid stenosis & $6(4.5 \%)$ & $2(33.3 \%)$ & 0.2048 \\
\hline
\end{tabular}

Table (1) showed significant correlation between HTN, DM, Dyslipidemia and BMI and postoperative complications as regard change in conscious level and insignificant correlation between carotid stenosis and these complications.

Table 2:- Correlation between risk factors and CVA

\begin{tabular}{|l|l|c|c|}
\hline Risk factor & No. of patients & Complications (no) & P. value \\
\hline HTN & $72(53.7 \%)$ & $2(2.7 \%)$ & $0.0177^{*}$ \\
\hline DM & $82(61.2 \%)$ & $4(4.9 \%)$ & $0.0006^{*}$ \\
\hline dyslipidemia & $110(82.1 \%)$ & $4(3.6 \%)$ & $0.0003^{*}$ \\
\hline Abnormal BMI & $112(83.6 \%)$ & $6(5.4 \%)$ & $0.0001^{*}$ \\
\hline Signif. carotid stenosis & $6(4.5 \%)$ & $2(33.3 \%)$ & 0.2048 \\
\hline
\end{tabular}

Table (2) showed significant correlation between HTN, DM, Dyslipidemia and BMI and postoperative complications as regard cerebrovascular stroke and insignificant correlation between carotid stenosis and these complications.
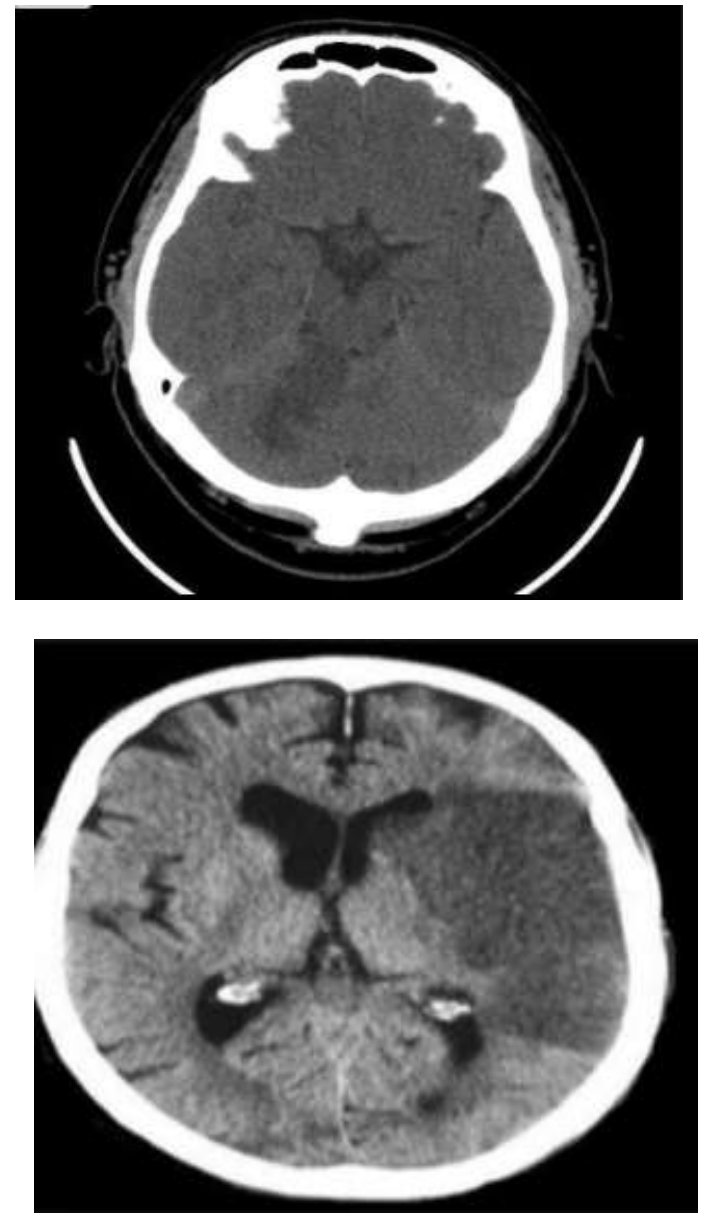

Fig. (1) A 67 year old male patient known with HTN, dyslipidemia, DM and obese, with postoperative right hemi-ataxia and truncal ataxia, CT showed right cerebellar infarction.
Fig. (2) A 71 year old male patient known with DM, Dyslipidemia, over weight and significant (52\%) left internal carotid artery stenosis, with postoperative right sided hemiplegia and right gaze palsy, CT brain showed left middle cerebral artery territory infarction. 


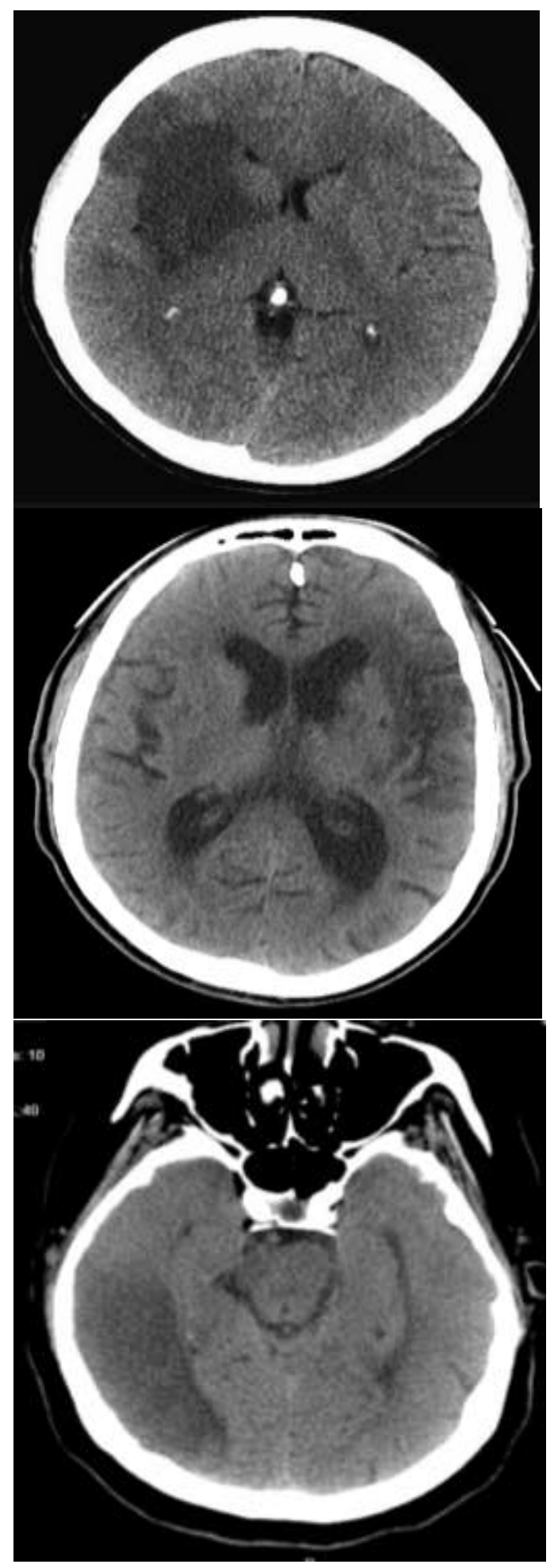

Fig. (3) A 56 year old male patient known with DM, dyslipidemia, obese and significant (50\%) right internal carotid artery stenosis, with postoperative left hemiplegia more in upper limb, CT brain showed right middle cerebral artery (upper branch) territory infarction.

Fig. (4) A 63 year old male patient known with HTN, dyslipidemia and obesity, with postoperative right sided hemiplegia and right gaze palsy, CT brain showed left middle cerebral artery territory infarction.

Fig. (5) A 72 year old male patient known with DM and obesity, with postoperative subtle left sided hemiparesis and visual impairment, CT brain showed right posterior cerebral territory infarction. 


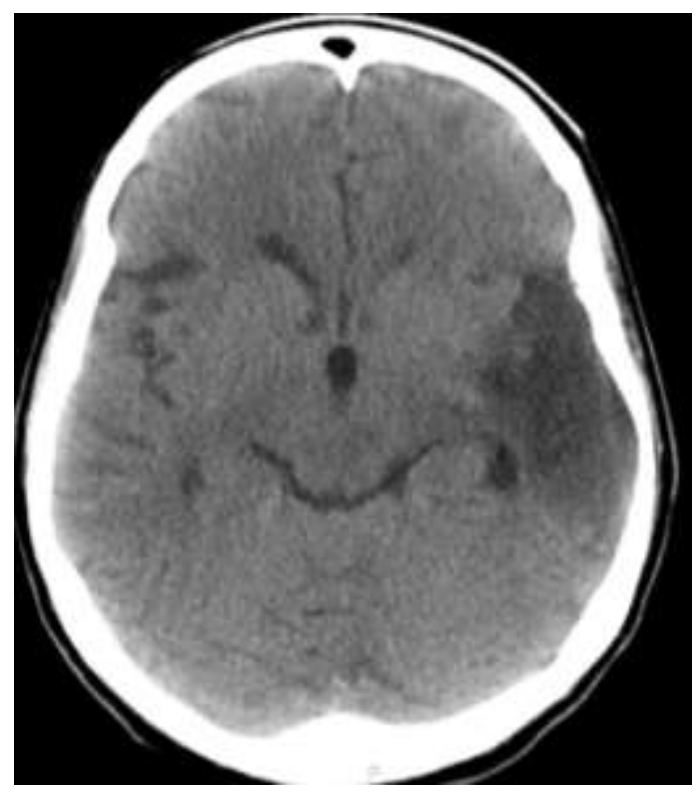

Fig. (6) A 57 year old male patient known with overweight, with postoperative right sided hemiplegia more in lower limb, CT brain showed left middle cerebral (lower branch) territory infarction.

\section{Discussion:-}

The CABG surgery is one of the most prevalent surgeries throughout the world that many patients are undergone this surgery annually. The neurologic complication after the CABG surgery is one of the most prevalent and most costly postoperative complications. In this study, 54\% had HTN, 61\% had diabetes, $82 \%$ had dyslipidemia, $4.5 \%$ had significant $(\geq 50 \%)$ carotid stenosis and $84 \%$ had abnormal BMI. The incidence rates of postoperative HIE, seizure disorder (NCSE) and CVA were 3\%, $1.5 \%$ and $4.5 \%$ respectively. No mortality due to neurological complications was observed in this study. Of total studied patients, the following percentages of patients were affected with postoperative neurological complications: $9.7 \%$ of diabetic patients, $5.5 \%$ of patients with HTN, $9 \%$ of patients with dyslipidemia, $10.7 \%$ of patients with abnormal BMI and $66.6 \%$ of patients with significant carotid stenosis. Statistically significant correlation was observed between HTN, DM, dyslipidemia and BMI and the incidence rate of disturbed LOC (P- value: 0.0177, 0.0006, 0.0001 and 0.0001 respectively) but the correlation was insignificant (P- value: 0.2048) for carotid stenosis as a risk factor. Regarding the HTN as a risk factor for postoperative neurologic complications, the results of the present study, there was a significant relationship and that agreed with $^{10-13}$ they found that a significant and clear relationship between the history of HTN and the prevalence of postoperative neurologic complications, our results disagreed with ${ }^{14,15}$ they reported no or poor relationship between hypertension and prevalence of postoperative neurologic complications. Regarding DM as other risk factor in our study, we found a significant correlation between DM and postoperative neurologic complications, this result was agreed with ${ }^{16-22}$ they found a significant correlation between DM and postoperative neurologic complications and disagreed with ${ }^{10-13}$ they found no significant correlation between DM and postoperative neurologic complications. Another risk factor which is dyslipidemia, in this study, there is a significant correlation between it and postoperative neurologic complications; this is agreed with ${ }^{23-29}$ they found a strong and significant correlation between dyslipidemia and postoperative neurological complications. In this study, another risk factor is BMI; we find a significant correlation between BMI and postoperative neurologic complications and this result was agreed with $^{30-32}$ they found that BMI was a significant risk factor for prevalence of neurologic complications after CABG surgery, while this result disagreed with ${ }^{33}$ who found that BMI has no impact on postoperative neurological complications. Another risk factor which is studied in this study is the severity of carotid artery stenosis that its diagnosis and measurement was performed preoperatively using the color Doppler ultrasound, we find no significant correlation between carotid stenosis and postoperative neurologic complications and our result was agreed with ${ }^{34,35}$ they reported no significant correlation between carotid stenosis and postoperative neurologic complications. This result can be indicative of this fact that this type of carotid artery stenosis cannot itself alone be a risk factor for the neurologic complications after the CABG surgery and it may be hazardous only when accompanied by other risk factors. ${ }^{36-39}$ disagreed with our result as they reported significant correlation between carotid stenosis and postoperative neurologic complications. 


\section{Conclusion:-}

Proper control of HTN, DM, Dyslipidemia and obesity and proper selection of patients for CABG surgery, well improved the general outcome after surgery and decrease post-operative neurological complications.

\section{Abbreviations:-}

CABG: coronary artery bypass graft, DM: diabetes mellitus, HTN: hypertension, BMI: body mass index, NCSE: non convulsive status epilepticus, HIE: hypoxic ischemic encephalopathy, CVA: cerebro-vascular accident, LOC: loss of consciousness, CT: computed tomography, EEG: electero-encephalography.

\section{Refrences:-}

1. Selnes OA, Mckhann GM. Coronary artery bypass surgery and the brain. N Engl J Med 2001; 334(6): 451-2.

2. José L. Pérez-Vela,a Ana Ramos-González,b Luis F. López-Almodóvar,and et al, Neurologic Complications in the Immediate Postoperative Period After Cardiac Surgery. Role of Brain Magnetic Resonance Imaging, Rev Esp Cardiol. 2005;58(9):1014-21.

3. Harrison MJ. Neurologic complications of coronary artery bypass grafting: Diffuse or focal ischemia? Ann Thorac Surg 1995; 59(5): 1356-1358.

4. Loponen P, Taskinen E, Laakkonen J, et al. Perioperative stroke in coronary artery bypass patients. Scand J Surg 2003; 92(2): 148-155.

5. Furlan AJ, Craciun AR. Risk of stroke during carotid artery bypass graft surgery in patients with internal carotid disease documented by angiography. Stroke 1985; 16(5): 797-799.

6. Newman MF, Kirchner BS, Philips-Bute B, et al. Longitudinal assessment of neuro cognitive function after coronary-artery bypass surgery. N Engl J Med 2001; 344(6): 1876.

7. Dacey LJ, Likosky DS, Leavitt BJ, et al. Perioperative stroke and long-term survival after coronary bypass graft surgery. Ann Thorac Surg 2005; 79(2):532.

8. Breuer AC, Furlan AJ, Hanson MR, Lederman RJ, Loop FD, Cosgrove DM, et al. Central nervous system complications of coronary artery bypass graft surgery: prospective analysis of 421 patients. Stroke. 1983;14:682-7.

9. Sid Gilman, MD, Neurological Complications of Open Heart Surgery, American Neurological Association 1990; 475-76.

10. Ali Changizi ,1 Ameneh Barikani,*2 Hossein Mojdehipanah,3 Ehsan Yazdi, Risk Factors of Early Neurologic Complications after CABG Surgery, Zahedan J Res Med Sci 2013 Apr; 15(4): 33-38.

11. Redmond JM, Greene PS, Goldsborough MA, et al. Neurological injury in cardiac surgical patients with a istory of stroke. Ann Thorac Surg 1996; 61(1): 42-47.

12. Kouchoukos NT, Wareing TH, Daily BB and Murphy SF. Management of the severely atherosclerotic aorta during cardiac operations. J Card Surg 1994; 9(5): 490-494.

13. Herlitz J, Wognsen GB, Haglid M, et al. Risk indicators for cerebro vascular complications after coronary artery bypass grafting. Thorac Cardiovasc Surg 1998; 46(1): 20-24.

14. Newman MF, Kirchner BS, Philips-Bute B, et al. Longitudinal assessment of neuro cognitive function after coronary-artery bypass surgery. N Engl J Med 2001; 344(6): 1876.

15. Janssen DP, Noyez L, van Druten JA, et al. Predictors of neurological morbidity after coronary artery bypass surgery. Eur J Cardiothorac Surg 1999; 15(2): 166-172.

16. Newman MF, Wolman R, Kanchuger M, Marschall K, Mora-Mangano C, Roach G, Smith LR, Aggarwal A, Nussmeier N, Herskowitz A, Mangano DT. Multicenter preoperative stroke risk index for patients undergoing coronary artery bypass graft surgery. Multicenter Study of Perioperative Ischemia (McSPI) Research Group. Circulation. 1996;94(9 Suppl): II74-II80.

17. Engelman DT, Cohn LH, Rizzo RJ. Incidence and predictors of TIAs and strokes following coronary artery bypass grafting: report and collective review. Heart Surg Forum. 1999;2:242-245.

18. Ascione R, Reeves BC, Chamberlain MH, Ghosh AK, Lim KH, Angelini GD. Predictors of stroke in the modern era of coronary artery bypass grafting: a case control study. Ann Thorac Surg. 2002;74:474-480.

19. Charlesworth DC, Likosky DS, Marrin CA, Maloney CT, Quinton HB, Morton JR, Leavitt BJ, Clough RA, O'Connor GT. Development and validation of a prediction model for strokes after coronary artery bypass grafting. Ann Thorac Surg. 2003;76:436-443.

20. Stamou SC, Hill PC, Dangas G, Pfister AJ, Boyce SW, Dullum MK, Bafi AS, Corso PJ. Stroke after coronary artery bypass: incidence, predictors, and clinical outcome. Stroke. 2001;32:1508-1513. 
21. McKhann GM, Goldsborough MA, Borowicz LM Jr, Mellits ED, Brookmeyer R, Quaskey SA, Baumgartner WA, Cameron DE, Stuart RS, Gardner TJ. Predictors of stroke risk in coronary artery bypass patients. Ann Thorac Surg. 1997;63:516-521.

22. McKhann GM, Grega MA, Borowicz LM Jr, Bechamps M, Selnes OA, Baumgartner WA, Royall RM. Encephalopathy and stroke after coronary artery bypass grafting: incidence, consequences, and prediction. Arch Neurol. 2002;59:1422-1428.

23. Orit Kluck Marius Berman Alon Stamler Gideon Sahar Alexander Kogan Eyal PoratAlexander Sagie; Value of echocardiography for stroke and mortality prediction following coronary artery bypass grafting. Interactive CardioVascular and Thoracic Surgery, 2007; 6 (1):30-34.

24. M. Maganti, V. Rao, S. Brister and J. Ivano; decreasing mortality from coronary artery bypass grafting in octogenerians. Canadian j of cardiology 2009; 25(2): 32-35.

25. Francisco Nicolini, Anderea Agostinelli, Antonella Vezzani, Tullio Manca and et al; the evaluation of cardiovascular surgery in elderly patients: A review of current options and outcomes. Biomed Research international 2014; 2: 1-10.

26. Nashef SA., Roques F., Michel P., Gauducheau E., Lemeshow S. and Salamon R. European system for cardiac operative risk evaluation (Euro SCORE) Eur. J. Cardiothorac. Surg. 1999; 16: 9-13.

27. Jamal Kabeer Khan, Syed Shahabuddin, Sheema Khan, Gulshan Bano and et al., coronary artery bypass grafting in south Asian patients: impact of gender. Ann Med Surg (lond) 2016; 9: 33-37.

28. Maryam Ardeshiri, Zahra Faritus, Zahra Ojaghi-Haghighi, Hooman Bakhshandeh and et al., Impact of metabolic syndrome on mortality and morbidity after CABG surgery. Res Cardiovasc Med 2014; 3(3): 17-20.

29. Ron T. Van Domburg, Arie Piter Kappetein, ad J.J.C. Bogers; the clinical outcome after coronary bypass surgery: A 30 year follow up study, European Heart Journal 2009; 30(4): 453-458.

30. Parsonnet V, Dean D, Bernstein AD. A method of uniform stratification of risk for evaluating the results of surgery in acquired adult heart disease. Circulation 1989;79 Suppl I:I3-12.

31. Edwards FH, Carey JS, Grover FL, Bero JW, Hartz RS. Impact of gender on coronary bypass operative mortality. Ann Thorac Surg 1998;66:125-31.

32. Prasad US, Walker WS, Sang CTM, Campanella C, Cameron EWJ. Influence of obesity on the early and long term results of surgery for coronary artery disease. Eur J Cardiothorac Surg 1991;5:67-73.

33. Barnaby C. Reeves, Raimondo Ascione, Martin H. Chamberlain and Gianni D. Angelini. Effect of Body Mass Index on Early Outcomes in Patients Undergoing Coronary Artery Bypass Surgery. JACC, 2003; 42 (4):66876.

34. Chang G, Luo HD, Emmert MY. Predictors of adverse neurological outcome following cardiac surgery. Singapore Med J 2009; 50(7): 679.

35. Bucerius J, Gummert JF, Borger MA, et al. Stroke after cardiac surgery: A risk factor analysis of 16,184 consecutive adult patients. Ann Thorac Surg 2003; 75(2): 472-8.

36. McKhann GM, Grega MA, Borowicz LM Jr, Bechamps M, Selnes OA, Baumgartner WA, Royall RM. Encephalopathy and stroke after coronary artery bypass grafting: incidence, consequences, and prediction. Arch Neurol. 2002;59:1422-1428.

37. Bucerius J, Gummert JF, Borger MA, Walther T, Doll N, Falk V, Schmitt DV, Mohr FW. Predictors of delirium after cardiac surgery delirium: effect of beating-heart (off-pump) surgery. J Thorac Cardiovasc Surg. 2004;127:57-64.

38. Rudolph JL, Babikian VL, Birjiniuk V, Crittenden MD, Treanor PR, Pochay VE, Khuri SF, Marcantonio ER. Atherosclerosis is associated with delirium after coronary artery bypass graft surgery. J Am Geriatr Soc. 2005;53:462-466.

39. Santos FS, Velasco IT, Fraguas R Jr. Risk factors for delirium in the elderly after coronary artery bypass graft surgery. Int Psychogeriatr. 2004;16:175-193. 